\title{
Advances in Information Provision from Wireless Sensor Networks for Irrigated Crops*
}

\author{
Jagath C. Ekanayake, Carolyn B. Hedley \\ Landcare Research-Manaaki Whenua, Lincoln, New Zealand \\ Email: ekanayakej@landcareresearch.co.nz
}

How to cite this paper: Ekanayake, J.C. and Hedley, C.B. (2018) Advances in Information Provision from Wireless Sensor Networks for Irrigated Crops. Wireless Sensor Network, 10, 71-92. https://doi.org/10.4236/wsn.2018.104004

Received: February 15, 2018

Accepted: April 22, 2018

Published: April 25, 2018

Copyright $\odot 2018$ by authors and Scientific Research Publishing Inc. This work is licensed under the Creative Commons Attribution International License (CC BY 4.0).

http://creativecommons.org/licenses/by/4.0/ c) (i) Open Access

\begin{abstract}
Current advances in connected sensor technologies for near real-time environmental monitoring are transforming the quality of information provision to land managers. This "Third Industrial Revolution" that connects digital sensor data analytics with adaptive services aims to transform data processing for timely decision support. The information is needed to improve irrigation scheduling, because global demand for food relies heavily on irrigation and global freshwater resources are diminishing. Previously, practitioners used visual indicators, infrequent measurements or predictive water balance models to estimate irrigation schedules. Visual indicators and infrequent measurements are approximate, and predictive models require many inputs so that likely cumulative errors cause inaccuracies in scheduling. In contrast, wireless sensor networks enable near real-time continuous measurement of soil moisture at targeted positions providing the site-specific information required for precision irrigation scheduling and efficient freshwater management. This paper describes and compares the structure, build and implementation of Crossbow, DigiMesh, and LoRa systems to deliver information on spatio-temporal soil water status and crop stress to practitioners over smart phones and webpages to improve management of irrigated land. Our study found that the newer LoRA system has advantages over the other systems, especially on flat land, with furthest node range of $>10 \mathrm{~km}$ and advanced communication protocols that can penetrate dense vegetation. The mesh networking of the DigiMesh and Crossbow systems was preferred in hilly terrain to communicate around hills, and allows easy expansion of the network. The Crossbow system is simpler to install but presents difficulties for third party sensor integration. All systems allowed a step change in our ability to track dynamic changes in soil hydraulic properties and crop stress, to improve irrigation water use efficiency.
\end{abstract}

${ }^{*}$ WSNs for Precision Irrigation. 


\section{Keywords}

Micaz, ZigBee, DigiMesh, LoRa, Irrigation

\section{Introduction}

Three critical stages have been defined in a nation's economic evolution: 1) mechanical, 2) electrical, and 3) information technology [1]. It is the third stage that critically creates and delivers added value that is essentially intangible, processing data from a decision-making perspective to improve, for example, natural resource management and life quality in general. The recent "information explosion" utilizing sensors, communication and digital technologies, and cloud-based computer systems, has been termed the "Third Industrial Revolution". It provides spatiotemporally fine resolution measurements and the challenge is to manage this information within the context of societal and environmental needs [2] [3]. In the $21^{\text {st }}$ century, over $70 \%$ of globally allocated freshwaters are used by agriculture [4] [5] [6]. In developing countries, over $80 \%$ of freshwater is being used for irrigation. Increasing agricultural demand on freshwater is unsustainable in many parts of the world. To improve sustainable freshwater use by agriculture it is imperative to improve irrigation efficiency [7].

A major problem with traditional irrigation scheduling is that a fixed amount of irrigation water is typically applied at one time based on a simple decision-making process that might use, for example, knowledge of soil moisture, climate and crop stage through visual inspection or simple models. This uniform application approach often leads to over-irrigation of some parts of the land, sometimes causing excess drainage, while other parts are under-irrigated resulting in yield loss. With a clear understanding of the benefits of varying irrigation according to spatial differences e.g. [6], one of the key pieces of information that practitioners now demand to improve irrigation efficiency is timely information about the spatial differences in soil water status at appropriate scales [8] [9]. In the past, soil, climate and crop data have been fed into predictive water balance models to estimate irrigation scheduling. Although these numerical models were developed to obey the law of physics and mathematics, they rely on the quality of the environmental parameter inputs such as crop growth stage, evapotranspiration, soil water-holding capacity, and relative humidity. The accuracy of the predictive results is therefore only as good as the accuracy of the parameters fed into these models [10] [11]. A 2-mm over-estimation of weekly irrigation for a 100 -ha farm by a predictive model would waste over $50,000 \mathrm{~m}^{3}$ freshwater seasonally. This is a financial loss and also increases risk of contaminant leakage in drainage waters. Saved water can be allocated elsewhere to increase crop production, especially relevant where there are freshwater resource constraints.

Therefore the challenge is to develop a method that continually measures soil moisture through crop growth stages to inform irrigation timing and reduce 
water stress, because this has been shown to improve irrigation water use efficiency and crop yield [6] [7] [12]. Indeed, there is evidence to show that soil moisture monitoring can be the most important piece of information for accurate irrigation scheduling [13]. As a result, and with the affordability of new soil moisture-sensing technologies, many practitioners have taken up direct soil moisture monitoring-based irrigation scheduling [10]. After a 4-year simulation at 5 sites, water savings of up to $27 \%$ were reported using a variable rate irrigation (VRI) system using software with individual sprinkler control to spatially vary irrigation informed by near-real-time soil moisture monitoring [14]. Other researchers found that time-based irrigation control with direct soil moisture monitoring saved irrigation water by up to $47 \%$ [15]. Case studies conducted with commercial growers showed water saving of up to $25 \%$ could be achieved when direct soil moisture measured by a sensor network was adapted to control irrigation [16]. Irrigation based on direct soil moisture measurements has also been implemented by USDA in their Specialty Crops Research Initiative project [17]. These studies provide evidence for improved irrigation water use efficiency when irrigation scheduling is informed by soil moisture monitoring, but the degree of efficiency gains varies from site to site, depending on site-specific factors, such as the degree of soil variability.

Wireless sensor networks offer huge potential to provide timely, improved information to assist irrigation scheduling. Although the benefits of using direct soil moisture measurement to estimate irrigation scheduling have been recognized by practitioners, this proven technology was not available at high spatial and temporal resolution until the turn of the $21^{\text {st }}$ century, e.g. [18] [19]. As instruments used in the past to measure soil moisture data were bulky and expensive to use in large numbers, a predictive modelling approach was the common choice to estimate soil moisture for irrigation scheduling. However, recent advances in wireless technology using low-power digital radios operating in licence-free frequency bands allow direct continuous measurement of soil moisture, which is more appealing to practitioners than the predictive modelling approach. The limitations on network expandability of ZigBee WSN technology-the most common international standard protocol developed for building WSN networks-make it less appealing for monitoring soil moisture in the agricultural environment.

There is an increasing choice of wireless technologies available for customized builds, but comparative studies of their application to irrigation scheduling do not exist. We therefore reviewed and compared available technologies, by designing, building and successfully testing customized sensor networks using the Crossbow, DigiMesh, and LoRA protocols. This paper presents findings from this comparative study. The objectives of this paper are to 1) compare three WSN protocols for irrigation scheduling, 2) describe how WSNs enable soil moisture status and crop water stress to be monitored in near real time to inform irrigation scheduling decisions, and 3) describe how WSNs provide new 
and important insights into dynamic changes in soil hydraulic characteristics to assist efficient management of irrigated land.

\section{Materials and Methods}

\subsection{Wireless Sensor Network System Options}

Wireless sensor networks (WSNs) consist of sensors connected to nodes that wirelessly communicate through a common gateway to remote end users via apps, web pages, or direct control of devices. A wide range of environmental sensors may be connected to the nodes. Each node typically consists of a micro-controller, supporting electronics, and a radio communication module. There are different protocols for node distribution and communication (topology). The two main WSN topologies are star topology and mesh topology. Star topology, a commonly used assemblage of nodes, has two types of nodes: 1) one coordinator node and 2) many end nodes (Figure 1(a)). Usually end nodes are sleep-enabled, which means they can "wake-up" at regular defined intervals, exchange data with the gateway, then return to rest mode. The gateway is responsible for forwarding sensor data to cloud servers via a cellular or satellite modem. The star topology is a reliable topology but the system has a single point of failure: because end nodes sleep most of the time they are unable to pass data between themselves to the gateway. However, this does enable the end node to have a long battery life. Mesh topologies are much more flexible when it comes to communication, with nodes typically able to route data between themselves until they reach a designated destination-and this destination is typically a coordinator or gateway that is responsible for either logging or forwarding the data to an external network. Nodes in a "Peer to Peer" mesh network (termed "p2p") have equal rights to receive and transmit data to the coordinator (Figure 1(b)). A router within the network can behave as an end device, which saves

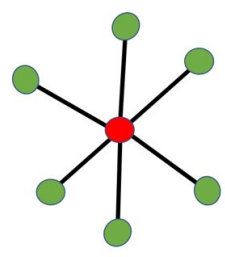

(a) Star
- Router

- End nod

- Coordinator

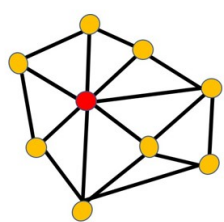

(b) Peer to Peer Mesh

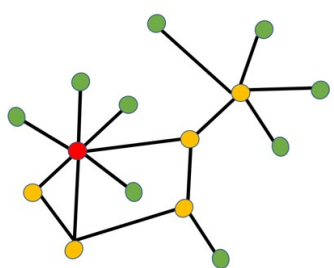

(d) Zigbee

(c) Digimesh

Figure 1. Different wireless sensor network topologies. 
power, but must be main powered as it cannot sleep. Mesh networks are capable of interconnecting sensor nodes with each other using multiple pathways that are updated and optimized dynamically. This allows sensor nodes to self-discover, self-organise, and self-heal to derive the most energy-efficient pathways to relay data to a gateway (Figure $1(\mathrm{c})$ ). Sensor nodes can be routers or sleep-enabled, depending on power constraints (sleeping end nodes use less power but cannot route data).

\subsubsection{ZigBee Mesh Networks}

ZigBee [19] is a wireless technology developed as an open global standard to create low-cost, low-power, machine to machine (M2M) wireless networks (Figure 1(d)). The ZigBee standard operates on the IEEE 802.15.4 physical radio specification in unlicensed bands including $2.4 \mathrm{GHz}, 900 \mathrm{MHz}$, and $868 \mathrm{MHz}$ (Institute of Electrical and Electronic Engineers, IEEE). Over 300 leading semiconductor manufacturers, technology firms, OEMs, and service companies are members of the ZigBee Alliance. Because it is an international standard, sensors from different ZigBee Alliance members are easily interchangeable in a ZigBee sensor network and ZigBee is therefore a popular choice for wireless monitoring sensor networks [20]. ZigBee protocols define three types of nodes-coordinators, routers, and end devices-requiring one coordinator per network (Figure 1(d)). End devices are low-power, sleep-enabled devices that cannot relay data to the coordinator from other devices in the network. This inability of end devices to relay data is the major disadvantage of ZigBee protocols because main-powered additional routers capable of relaying data to other devices are essential to expand the sensor networks.

\subsubsection{DigiMesh Networks (Full Mesh)}

In contrast to the ZigBee networks, which have three node types, the DigiMesh networks have only one type of node, which can act as a coordinator, router or end device. This allows the formation of an expandable, simple, and reliable mesh network as routers may come and go through interference and damage in open agricultural environments. A comprehensive description of the two systems is given in [21] and [22]. As DigiMesh was developed by Digi International without affiliation with any other organization, the technology is not compatible with other commercially available radios. However, if used as the data transport layer, DigiMesh is more suitable than any other technology for forming sleeping sensor networks. Given that DigiMesh allows all nodes, including the coordinator, to sleep and therefore to reduce power consumption, the nodes can be battery powered. Currently, ZigBee allows only end devices to sleep but not routers or coordinators. The sleeping of any sensor node is achieved by time synchronization. The major advantage of the DigiMesh networks is that they eliminate the single point failure associated with relying on a single coordinator. DigiMesh establishes time synchronization through a nomination and election process to select a suitable coordinator if necessary, enabling the network to operate auto- 
nomously. After time synchronization, all sensor nodes wakeup in unison, exchange data, and go back to sleep.

\subsubsection{TinyOS Operating System for Sensor Network Nodes MICA Technology}

Early in the 21st century, researchers at University of California, Berkeley, pioneered an open-source hardware and software platform that led to a single package of sensing, communications and computing. U.C. Berkeley, U.C. Los Angeles, Intel Research Labs, Robert Bosch Corp., U.S. Air Force Research Labs, and Crossbow Technology were the main contributors to the development of the early wireless MICA sensor nodes [23]. MICA hardware consists of a series of thin processors, radios and sensor interfaces sandwiched together to create a wireless smart sensor, enabling advances in low-power CMOS electronic hardware. One of the main constraints for developing an operating system for this embedded system was optimization of energy and memory in the smallest hardware footprint possible. This was a major challenge for the wireless sensor network tasks: sensor measurement, routing data with minimum energy consumption. To meet this challenge, researchers at U.C. Berkeley developed an operating system called TinyOS that allows the networking, sensor measurements, and efficient power management with tight memory constraint. Crossbow Technology was one of the very first to adopt MICA technology and to build thousands of wireless sensor nodes for commercial use.

\subsubsection{LoRa Technology}

The LoRa Alliance, one of the most popular and fastest growing technology alliances, is a non-profit association of more than 500 member companies around the world. Their commitment is to develop Low Power Wide Area Networks (LPWAN) within the Internet of Things (IoT) through the development of, and promotion of, the LoRaWAN open standard. The LoRA radios use an unlicensed radio spectrum in the industrial, scientific, and medical (ISM) bands to enable low power wide area communication from remote sensors to multichannel gateways connected to the cloud (https://www.semtech.com/technology). The technology claims a battery life over 20 years, with LoRa connected sensors having a range of over $10 \mathrm{~km}$ in line of sight (LOS) and $3 \mathrm{~km}$ in urban areas. Having recognised the potential of these major benefits of the LoRa technology, many leading cellular service providers around the world have begun to install multi-channel LoRa gateways, enabling researchers and enthusiasts to connect their LoRa enabled sensors to the internet. The Things Network is a LoRa Alliance project to start building a network for the internet based on LoRaWAN, which does not require $3 \mathrm{G}$ WiFi.

\subsection{Data Delivery Systems}

The goal of a wireless sensor network is to send measured sensor data to web servers where they are stored in databases and made available to remote end us- 
ers. This last step is typically accomplished over the internet, via smart phone apps, or compatible web browsers using state-of-the-art data visualization tools. Two common methods available to transport data to web servers are:

1) Option 1: a mesh sensor network that gathers data into a base station (Gateway) linked to the internet via a cellular network;

2) Option 2: each sensor node, in a star topology, is linked to the internet via a cellular network, creating a mesh sensor network on the cellular network.

Option 1 is more affordable because Option 2 becomes very expensive as the number of sensor nodes in the network increases, with each node requiring a dedicated SIM card and cellular connection with the data package. We trialled both options, and adopted Option 1 to monitor soil moisture at farms where cellular coverage was very weak and patchy. In this case, locating the gateway at a suitable point enabled the use of a high-gain Yagi antenna to connect it to a cell tower over $40 \mathrm{~km}$ away.

\subsection{The Sensors}

Crossbow, DigiMesh and LoRa WSNs were custom built to monitor: 1) soil moisture, and 2) crop canopy temperature to inform irrigation scheduling. WSNs enable data to be collected at high temporal frequency and with low latency compared with conventional measurement methods, thus providing new information about dynamic changes in soil hydraulic properties and crop water stress.

Soil moisture was monitored using capacitance sensors (Delta-T Devices Ltd SM300 and ML2; Aquachek probes (Aquacheck USA@)) to inform irrigation scheduling. The effect of temporally variable soil hydraulic properties on soil water dynamics has previously been identified by other researchers [24] [25] [26] [27] [28], but these observations were based on spot measurements at one point in time (e.g. physical soil sampling once a day), while the WSN technology provides a much richer dataset for investigating dynamic changes in soil hydraulic properties, e.g. pore size distribution changes after tillage, compaction, rain events and time [29]. The degree of soil compaction has a considerable influence on soil hydraulic properties such as infiltration rate, soil water retention, hydraulic conductivity and hydraulic response [30] [31]. Soil compaction can easily change over a few days, especially in very wet soils, due to, e.g. overgrazing by heavy animals or use of heavy farm machinery. The main cause of temporal change in soil hydraulic characteristics has been identified as the change in pore space distribution and soil structure. The effect of soil volume change on soil properties was recognized as early as 1917 [32], and further studies on the effect of compaction and tillage operations on bulk density and total porosity have also been well-researched [33]-[38]. The size, shape, continuity and tortuosity of pores largely controls soil hydraulic characteristics, [39] [40] [41]. The high temporal resolution and data delivery systems of these WSNs provide a step change in the way that we can observe how wetting and drying patterns impact 
on these soil hydraulic properties.

Apogee infrared radiometer sensors (Apogee IR radiometer Model IP67 marine grade SI-411l with SDI-12) were also connected into the WSN to monitor crop canopy temperature. In conjunction with the concurrent air temperature, crop canopy temperature can be used to estimate crop water stress [42] [43] [44]. This estimation relies on the principle that transpiration from a well-watered crop cools the plant, but when the ratio of canopy temperature increases with respect to air temperature, this indicates a level of water stress as a result of the reduction of transpiration caused by limited soil water supply. Non-contact infrared radiometers have been previously used manually to collect spot measurements of canopy temperature. However, the ability to connect IR radiometers to WSNs provides a new and easy method to continuously monitor plant water stress. This also has an advantage over remote sensing methods that rely on infrequent flight paths over the area of interest by aeroplanes, drones and satellites, e.g. [45] [46] [47].

\subsection{Positioning the Sensors}

WSN-enabled nodes were placed in multiple positions within a target area to simultaneously monitor soil and crop parameters. This approach required a spatial optimization process to guide positioning of the nodes. The method selected in this study was to use a detailed soil map, or, where this was not available, a proximal soil sensor survey system to map the study area at high resolution and derive a map of soil variability. Statistical analysis of the sensor data was used to stratify the area and to guide a stratified random sampling design [6] [48]. The proximal soil sensor was an electromagnetic (EM) sensor that measures the apparent electrical conductivity (EC) of the soil in millisiemens per meter $(\mathrm{mS} / \mathrm{m})$. The sensor predominantly responds to soil texture and moisture differences under non-saline conditions [49]. Soil texture and moisture characteristics are two guiding attributes for soil classification, and therefore provide a powerful method to quantify soil variability in a way that reflects soil differences related to water storage characteristics.

\subsection{Case Study 1: Crossbow WSN System}

The first case study used a wireless sensor network for real time soil moisture monitoring created using Crossbow Technology products

(https://www.memsic.com/). The WSN comprised Original Equipment Manufacturer (OEM) module-based reference hardware and sensor data acquisition modules with a cellular-enabled gateway using a mini-tablet running the Ubuntu open source operating system (a GNU/Linux distribution based on Debian). The base station had a separate radio and processor board for connecting to the WSN. Collected sensor data from the wireless sensor nodes were stored in a MySql database on the base station and visualized using Mote View visualization software running on the base station server over the internet. 
This Crossbow wireless sensor network was installed on a commercial cropping farm $100 \mathrm{~km}$ south of Christchurch, New Zealand. The sensor nodes were installed in an area of 100 ha in different soil zones as guided by the soil map (Figure 2). Two soil moisture sensors (Delta-T SM300) were attached to each node at a soil depth of $20 \mathrm{~cm}$ and $40 \mathrm{~cm}$ to monitor soil moisture in the majority of the root zones for the different crops. These Crossbow sensor nodes had a strict short-range $(\sim 500 \mathrm{~m})$ line of site. The true mesh networking capability of the Crossbow sensor network was tested as there was limited direct line of site between many wireless sensor nodes and the base station.

The Crossbow wireless sensor network was easily expandable as the network could self-form and self-organize with data hopping from one node to the other to transfer data to the base station; however, the network saves data in a database on a local server running on the base station, which makes the data vulnerable to being lost, i.e. it is not backed up. The web server running on the local base station provides the data visualization via a Mote View visualization interface (Figure 3). The number of sensor nodes required per area to form a mesh network increases with the targeted area due to the short transmission range of each node.

The advantages of this Crossbow WSN system were its capabilities of self-forming, self-organizing, and self-healing, but it lacked the cloud-based data storage and data visualization functions.

\subsection{Case Study 2: DigiMesh WSN System}

Digi International Inc. does not provide complete wireless sensor network

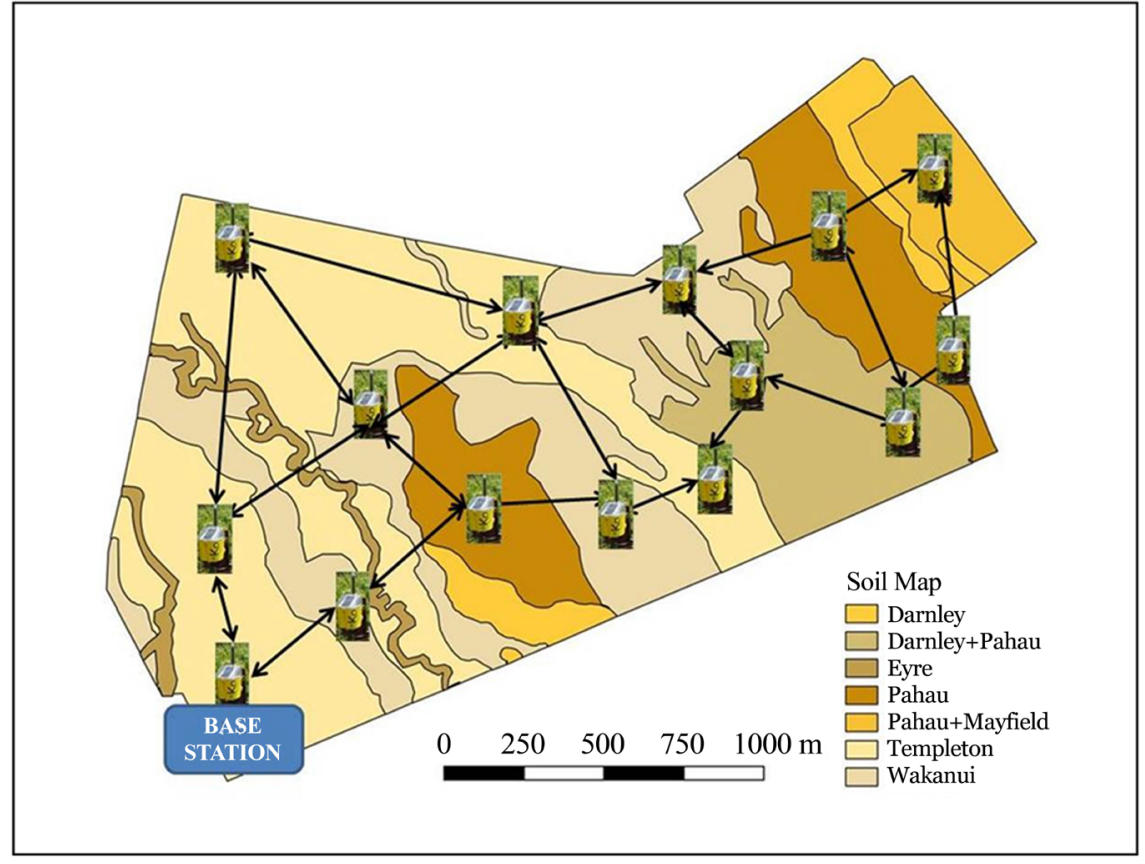

Figure 2. Freely expandable full mesh Crossbow wireless sensor network (eKo) with limited line of site between nodes and the base station (Case Study 1). 


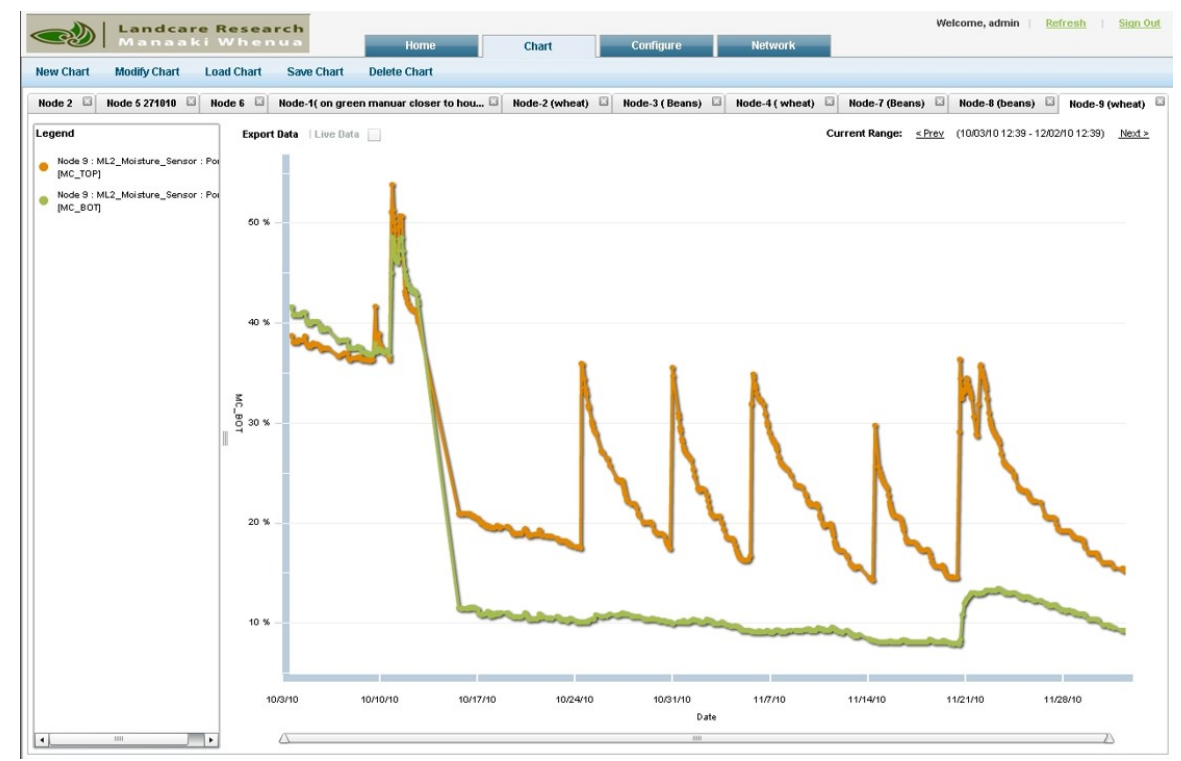

Figure 3. Mote View real time data visualisation interface running on the local server at the base station. Soil moisture profiles at $20 \mathrm{~cm}$ (brown line) and $40 \mathrm{~cm}$ (green line). Note that irrigation water hardly reaches the bottom sensor at $40 \mathrm{~cm}$, indicating minimum drainage, and good irrigation practice.

solutions for monitoring sensors in an agricultural environment. Instead, they provide software IDE (Integrated Development Environment) and hardware tools to help customers develop their own wireless mesh networks using their low-power radio modules and cellular or satellite gateways.

The reason for selecting a proprietary DigiMesh system over well-established ZigBee alliance hardware was the easy expandability of the DigiMesh WSN. DigiMesh sleeping nodes are not only capable of routing data but also support true mesh networking options. This is the main advantage of using DigiMesh radios, which enables the WSN to be expanded with ease.

A range of DigiMesh radio modules covering licence free frequency bands 2.4 $\mathrm{HHz}, 900 \mathrm{MHz}$, and $868 \mathrm{MHz}$ are available depending on the country's radio spectrum management laws. We selected $2.4 \mathrm{GHz}$ radio modules with $60 \mathrm{~mW}$, DSSS (Direct Sequence Spread Spectrum), which are allowed in New Zealand under free licence (General User Radio Licence for Short Range Devices https://gazette.govt.nz/notice/id/2017-go415).

Sensor nodes and sensors used in DigiMesh WSNs are shown in Figure 4. Wireless sensor nodes are installed in two soil zones according to the soil EC map (Figure 5). Two soil moisture sensors are attached to one node at each monitoring location to monitor soil moisture at two depths in the root zone. To increase mesh network reliability it is important to install the wireless sensor nodes in such a way that one node could directly communicate with at least two other nodes. This increases the robustness of the wireless mesh network by increasing the chances of self-healing and self-discovery. As all wireless nodes in the DigiMesh network are capable of routing data, this arrangement also helps expand the wireless network reliably. 


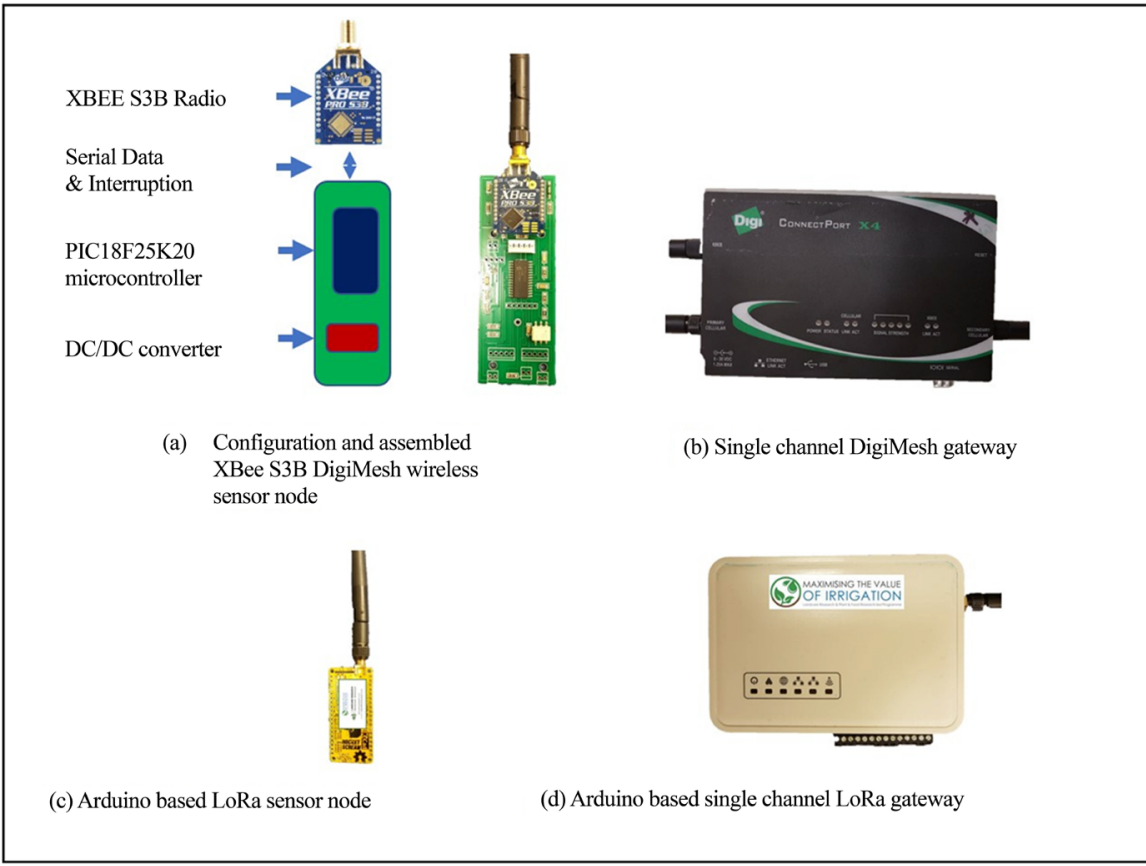

Figure 4. Hardware configuration of wireless sensor nodes with (a) XBee S3B DigiMesh radio from Digi International and PIC18F25K20 micro controller and (b) gateway; and (c) Arduino based LoRa sensor node and (d) LoRa gateway.

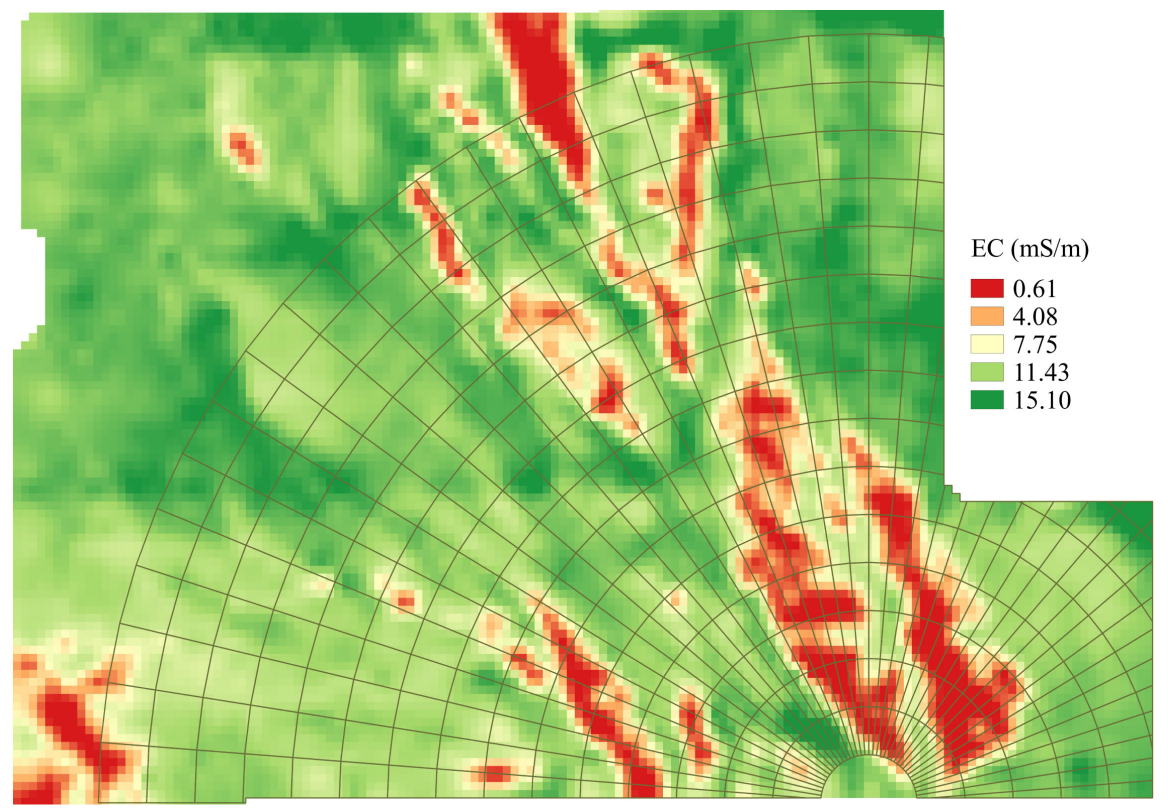

Figure 5. A DigiMesh WSN was installed into a 31-ha field to monitor soil moisture in two soil management zones (Zone 1: brown, stony at depth; Zone 2: green, stone-free). The map was derived from an electromagnetic (EM) sensor survey measuring apparent electrical conductivity (EC) in $\mathrm{mS} / \mathrm{m}$ (see Section 2.4).

The earlier DigiMesh sensor network nodes (https://www.digi.com) were designed in-house with XBEE S2B radio modules and in 2011 they were equipped with solar panels to cope with the continuous sleeping current of $\sim 260 \mathrm{uA}$. The 
sleep current was reduced to just below $50 \mathrm{uA}$ after the availability of low power version of DigiMesh (XBEE S3B) radios in 2016. These "Nano" nodes can operate over 1 year with three " $D$ " cell batteries and without solar backup.

The heart of a wireless sensor node is the XBee S3B module [50] to create the mesh data communication network layer, and a PIC18f25k 20 microcontroller to act as the interface between different sensors to the S3B radio (Figure 4(a)). The XBEE S3B radio itself can measure and send data from some basic sensors with analogue output without the help of a micro controller. However, it lacks the options to accommodate sensors with digital output (SDI-12), which was required for the IR radiometer sensors. Analog sensor outputs are converted to digital values by an on-board 10-bit ADC converter. The sensor nodes are powered by three $1.5 \mathrm{~V}$ Alkaline "D" cells which gives a total of $4.5 \mathrm{~V}$ initially. Ultralow voltage dropout $(100 \mathrm{mV})$ with $6 \mathrm{uA}$ quiescent current voltage regulator provides $3.3 \mathrm{~V}$ regulated power to the sensor node. This enables the sensor node to operate from $4.5 \mathrm{~V}$ right down to $3.4 \mathrm{~V}$ supply voltage. With a 49 -uA sleep current, the average battery lifetime of a sensor node can be greater than 2 years.

Most sensors used in this case study needed $5-12 \mathrm{~V}$ excitation, and power to them was supplied by a DC/DC converter via a digital pin of the microcontroller. All XBEE S3B DigiMesh radios in the network are configured to wake-up at regular intervals. Upon wake-up, the sleeping microcontroller is interrupted to take average readings of sensor outputs, transmitted through the serial interface to the XBEE S3B radio to the Gateway (Figure 4(b)). The node microcontrollers are also configured to monitor tipping-bucket rain gauges via a hardware interrupt triggered by a state change on one of the pins. Rain gauge inputs are fed to the microcontroller via an opto-isolator circuit to avoid interruption from electric fences.

A DigiMesh WSN was also constructed and run on a laboratory bench to calibrate soil moisture sensors before installation into the field. The sensors were installed into intact soil cores, which were then subjected to wetting (saturation) and draining (at $100-\mathrm{cm}$ suction) to simulate field conditions for three soil textures (Figure 6). The soil moisture content at $100-\mathrm{cm}$ suction is termed "field capacity" (FC) and aims to approximate the soil moisture at which a very wet soil ceases to drain. It is therefore the upper limit of soil moisture storage for plant use. The soil cores were placed on porous ceramic plates with a 0.5-bar air entry value, and these sat on electronic balances to enable estimation of gravimetric moisture content without having to remove them for weighing. Air drying was controlled by changing the relative humidity of the chamber using a dehumidifier. Soil moisture was recorded continuously and the data sent to a remote web page (Figure 6).

\subsection{Case Study 3: LoRa WSN System}

A LoRa sensor network was designed using commercially available modules with a LoRa radio and Arduino microcontroller imbedded on a single circuit board 


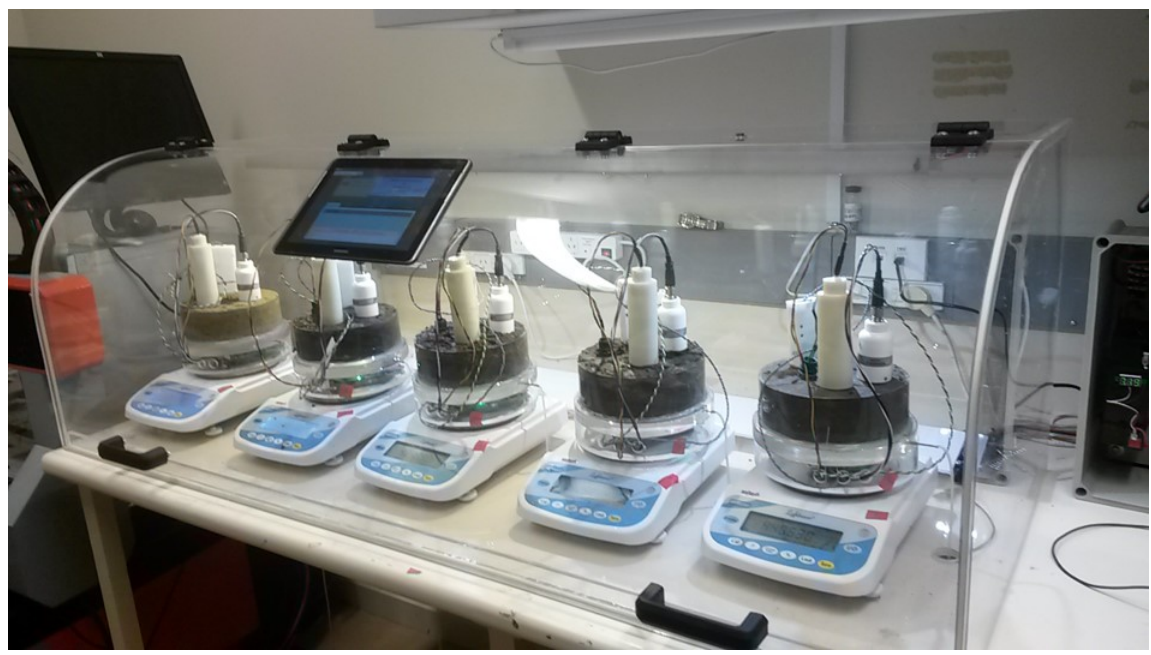

Figure 6. A DigiMesh WSN established in the laboratory for sensor calibration and investigation of dynamic changes in soil moisture through sequential wetting and drying cycles.

(Figure 4(c)). In New Zealand, LoRa radio operates on unlicensed frequency $915 \mathrm{MHz}-\mathrm{ISM}$ band. Arduino is an electronic software and hardware platform based on open source which is very easy to use

(https://www.arduino.cc/en/guide/introduction). The large membership of the Arduino community provides countless software libraries for professionals and enthusiasts to create electronic projects from extremely advanced to very simple (such as blinking an LED light). Thanks to the simplicity of the IDE and widely available libraries they are being tested even in primary schools. Availability of free software and cost-effective hardware enables the development of Arduino-LoRa sensor networks for a fraction of the resources required to build similar DigiMesh, ZigBee, and CrossBow sensor networks.

The LoRa gateway (Figure 4(d)) is a single channel, cellular enabled modem that gathers data from the sensor nodes and transmits to a personal cloud server rather than The Things Network. This enables total control of data handling for web and smart phone data visualization with minimal latency. The Arduino-LoRa module consumes sleep current as low as $4 \mathrm{uA}$, which was unachievable with other sensor nodes based on XBee radios. It allows battery life of a sensor node to be extended over 5 years with 3 " $D$ " cell batteries.

We therefore compared these three sensor network systems (Crossbow, DigiMesh, LoRa) in operational field conditions, and report our findings in the next section.

Sensors interfaced with the wireless sensor nodes were:

1) SM300 (single point soil moisture content) (Delta-T Devices Ltd.);

2) ML2 (single point soil moisture content) (Delta-T Devices Ltd.);

3) Aquacheck (6-point soil profile moisture content probe) (Aquacheck USA();

4) Infrared Radiometer (Apogee Electronics, USA). 


\section{Results}

\subsection{A Comparison of the Features of the Crossbow, DigiMesh and LoRa Systems Relevant to Their Application to Irrigation Scheduling}

The Crossbow system performed well in field conditions, but was unable to store data in cloud servers. Instead data are stored locally on a base station, which is interrogated remotely via a cellular or internet connection. If there is a power cut, the data cannot be accessed. However, it proved to be the easiest sensor network system to implement requiring least technical skills, and it included sensors specifically tailor-made to the Crossbow wireless sensor nodes. However, integration of other sensors, including the infrared radiometers was difficult, requiring professional electronic and software programming skills. We also noted that the polycarbonate housing for the solar panel deteriorated after one season reducing the solar recharging capacity. Although the Crossbow nodes are limited by their shorter range, their mesh networking capability allows the network to expand conveniently (Table 1 ).

Digi International provide good customer support through articles and tutorials for assembling DigiMesh wireless sensor network systems, although greater electronic and software programming skills were required to get the sensor network up and running, compared with the Crossbow and LoRa systems. Also, we were unable to find any science publications on the application of DigiMesh technologies to agricultural monitoring. Implementation of the full mesh networking proved to be challenging, although the long range sensor nodes with full mesh working capability enabled easy expansion of the sensor network to

Table 1. A comparison of the features of Crossbow, DigiMesh and LoRa WSN systems.

\begin{tabular}{|c|c|c|c|}
\hline \multirow{2}{*}{ Feature } & \multicolumn{3}{|c|}{ WSN System } \\
\hline & Crossbow & DigiMesh & LoRa \\
\hline Licence free (NZ) & Yes & Yes & Yes \\
\hline Frequency & $2.4 \mathrm{GHz}$ & $2.4 \mathrm{GHz}$ & $915 \mathrm{MHz}$ \\
\hline Range $(\mathrm{LOS})^{\mathrm{a}}$ & $500-1200 \mathrm{~m}$ & $900-1200 \mathrm{~m}$ & $>10 \mathrm{~km}$ \\
\hline Topology & Mesh & Mesh & Star \\
\hline Skills Required to Implement & Minimal & High & Medium \\
\hline $\begin{array}{c}\text { Third Party Sensor Integration } \\
\text { Skill Required }\end{array}$ & High & High & Medium \\
\hline Power Management & Solar Back-up & $\begin{array}{l}\text { Solar Back-up or } \\
\text { Battery Powered }\end{array}$ & $\begin{array}{c}\text { Battery } \\
\text { Powered, }>10 \text { years }\end{array}$ \\
\hline $\begin{array}{l}\text { Commercially available as } \\
\text { ready to deploy }\end{array}$ & Yes & No & Yes \\
\hline Technology & Propriety & Propriety & Alliance \\
\hline Data storage & Base station & Cloud server & Cloud server \\
\hline
\end{tabular}

${ }^{a}$ LOS: line of sight. 
cover very large areas with a lower number of nodes than the Crossbow technology. DigiMesh is the only system with a single type of node that acts as a coordinator, router or end node at any given time. Any DigiMesh node in the network could be selected as the coordinator by a nomination and selection process. All nodes wake up in unison, exchange data, synchronise their clocks, and go back to sleep. Wake up and sleep times can be varied remotely from a few seconds to one day. The system also allows immediate transfer of data via a gateway to a cloud database.

LoRa technology does not provide mesh networking and it relies on star topology. However, the ability of the LoRa ISM band radio to penetrate dense vegetation enables more extensive coverage on flat land (Table 1) compared with the DigiMesh and Crossbow systems that require nodes to be in line-of sight in order to transmit around obstacles such as forest and buildings. However, full mesh technology is preferred in hilly landscapes as an effective method to transmit around hills. The coordinator and the wireless sensor node radios with the same network address form a personal area network in the LoRa system. The LoRa star topology allows end nodes to sleep most of the time, extending the battery life up to 10 years depending on the type of sensors used.

\subsection{Visualization Tools for Using WSN Data to Inform Irrigation Scheduling Decisions}

Currently, the preferred way of making field data available to practitioners who participated in these trials is via easy-to-understand data visualization tools compatible with smart phones. The DigiMesh and LoRa systems enabled easy integration of data visualization tools, and Fusion Charts, a commercially available charting tool that has been customized using PHP software, was selected for this purpose. The entire web visualization code runs on a dedicated web server hosted on a commercial cloud-based service provider and streams near real-time data over the internet to standard web browsers on desktop PCs as well as on smart phones.

Two control lines are estimated and plotted with a soil moisture time series for each soil zone to indicate the two soil moisture limits (Figure 7). The field capacity (FC) line indicates the upper limit of the soil moisture content where drainage is likely to occur. The refill point (RF) line suggests that $60 \%$ of the plant-available water has been consumed. The best practice to conserve water with maximum yield is to maintain the soil moisture between the two control lines for the targeted zone, and these visualization tools provide a user friendly decision support tool for this purpose.

The Irrigation Map in Figure 7 provides an alternative visualization method to present the irrigation requirement for each soil zone, combining and simplifying information from Figure 5 and Figure 8. The measuring cylinder is a direct analogy to the two trend lines given in the soil moisture time series graph. The practitioner can decide the amount of irrigation to apply based on the 


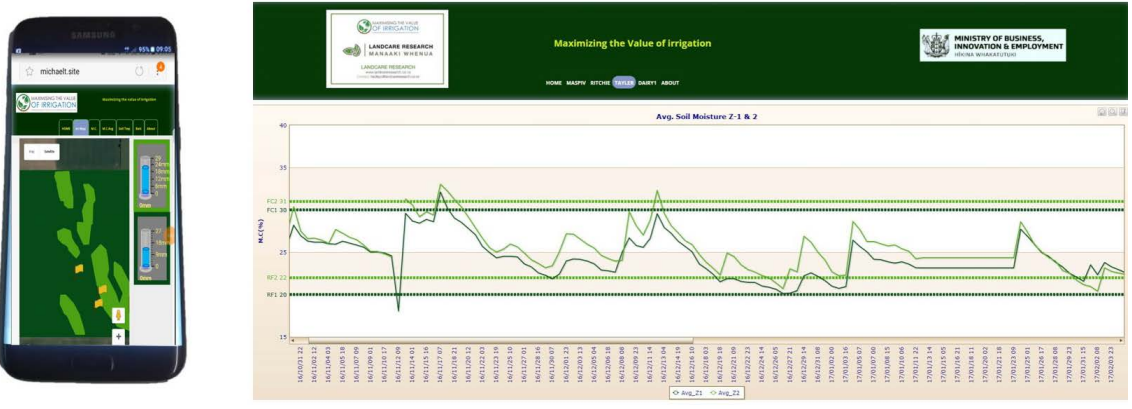

Figure 7. Screen shots of smart phone and tablet data visualisation. The best practise is to maintain the soil moisture between two trend lines: Field capacity and Refill lines.

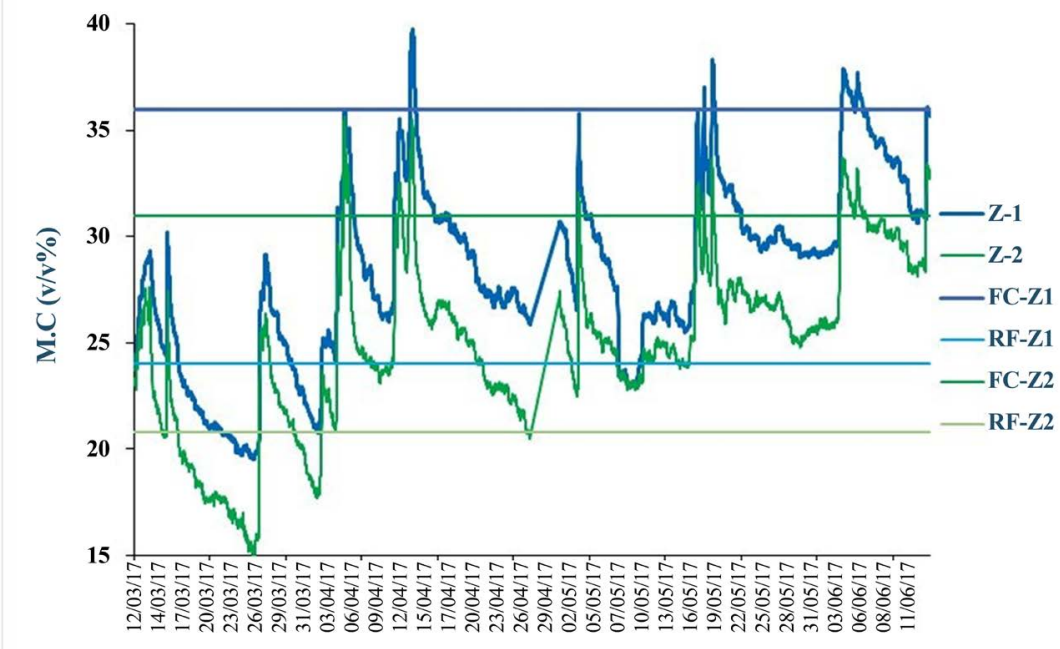

Figure 8. Time series of average soil moisture recorded by the DigiMesh WSN in two soil management zones. FC-Z1 (field capacity) and RF-Z1 (refill line) for Zone-1; FC-Z2 (field capacity) and RF-Z2 (refill line) for Zone-2 (as shown in Figure 5).

information that this provides. The empty measuring cylinder means $60 \%$ of plant available water has been consumed by the plants and it is time to irrigate. If the cylinders are still partially filled this indicates that some plant-available water is left in the soil. This pictorial visualization of irrigation requirements provided an intuitive, easy to understand decision support tool, and positive feedback was obtained from the practitioners who participated in these trials.

Our trials indicated that these WSNs provided a valuable tool for irrigation scheduling. However, in addition, they provided some new insights into the dynamic nature of soil hydraulic characteristics and crop stress, as discussed below.

\subsection{WSNs Track Dynamic Changes in Soil Hydraulic Properties}

The soil moisture graphs (Figure 7 and Figure 8) show how soil hydraulic properties are affected by climatic conditions, soil management and irrigation practice through time. A noticeable feature is the rapid soil moisture increase to 
field capacity and a sharp drop once soil moisture exceeds field capacity (e.g. Figure 3 and Figure 8). The rapid decrease after a significant wetting event to field capacity indicates that the soil has effective drainage characteristics-important information for the land manager. In addition, the data in Figure 8 show that the soil moisture at field capacity varies with time. In Figure 8, wetting and drying moisture profiles during the very first irrigation cycles after cultivation show lower field capacity values, suggesting that the disturbed soil matrix had a larger pore structure, with reduced ability to store water. Field capacity values derived from these dynamic soil moisture profiles tend to increase with subsequent irrigation cycles suggesting formation of a more stabilised soil matrix. These observations provide some evidence to suggest temporal change of soil hydraulic properties over time.

Further testing of this hysteresis effect with field capacity was carried out during the laboratory test for sensor calibration (Figure 6), as shown for two wetting and drying cycles in Figure 9. The results showed that the clay loam samples did not drop moisture content as rapidly as silt loam and sandy loam samples, when exposed to $100-\mathrm{cm}$ suction. The WSN technology enables continuous monitoring of the soil moisture curve to and beyond field capacity, and investigation of the drainage characteristics of these soils in a way that was previously impossible.

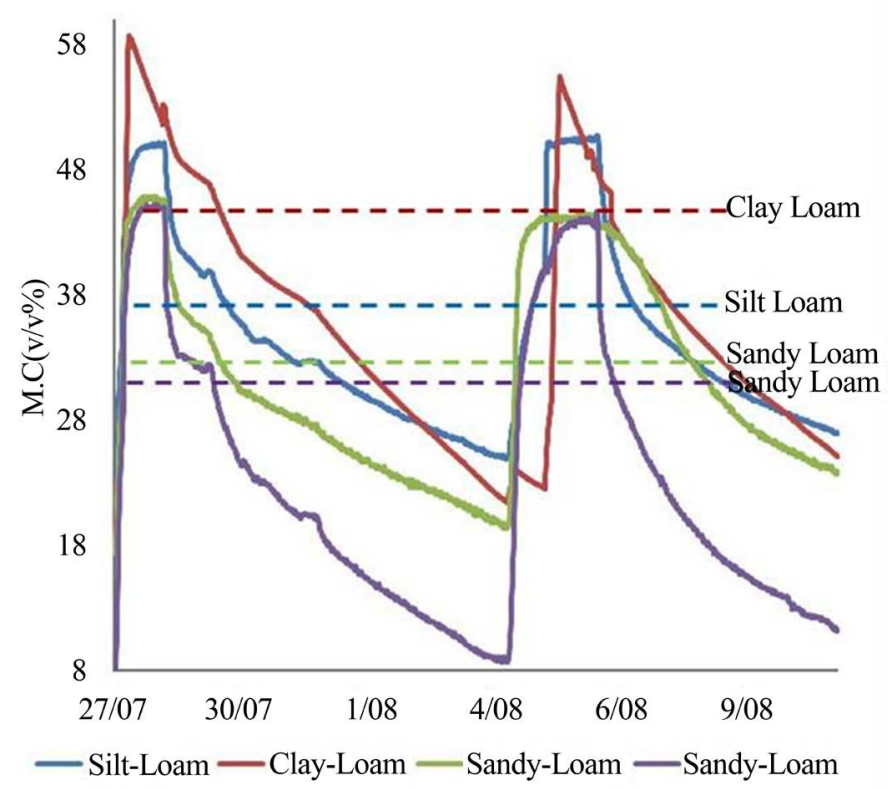

Figure 9. A WSN used in a laboratory experiments to track soil moisture through two wetting and drying cycles.

\subsection{WSNs Track Dynamic Changes in Crop Water Stress}

The canopy and instrument body temperature data acquired from the Apogee IR wireless sensor network were used to estimate a crop water stress index. The Apogee IR radiometer measuring radiation emitted from the target and instrument 
body temperature is capable of measuring temperature at a resolution of $0.05^{\circ} \mathrm{C}$. The sensor has a $22^{\circ}$ half-angle field of view and 1 second response time. The sensor network was designed with eight Apogee sensor nodes mounted on steel masts directed to view the crop directly from above. The measured canopy and instrument body temperatures for the summer and winter season of 2016/2017 are shown in Figure 10.

The data were converted to a crop water stress index, CWSI, using Equation (1) originally proposed by Jackson et al., 1981 [44]. The CWSI is calculated using the plant canopy temperature (Tc) (internally corrected using the body temperature), with air temperature (Ta) and atmospheric vapor pressure deficit (VPD).

$$
\mathrm{CWSI}=\frac{(\mathrm{Tc}-\mathrm{Ta})_{m}-(\mathrm{Tc}-\mathrm{Ta})_{l}}{(\mathrm{Tc}-\mathrm{Ta})_{u}-(\mathrm{Tc}-\mathrm{Ta})_{l}}
$$

Tc is the canopy temperature $\left({ }^{\circ} \mathrm{C}\right)$, Ta is the air temperature $\left({ }^{\circ} \mathrm{C}\right)$, and $m, 1$, and $u$, designate measured, lower baseline (well-watered), and upper limit (completely stressed) canopy-air temperature differences, respectively. The lower baseline can be calculated (Equation (2)) using the vapor pressure deficit (VPD) in $\mathrm{kPa}$, and the upper limit can be calculated (Equation (3)) using Ta and the saturated vapour pressure at $\mathrm{Ta}$ (VPsat) in $\mathrm{kPa}$.

$$
\begin{gathered}
(\mathrm{Tc}-\mathrm{Ta})_{1}=\operatorname{Intercept}+\operatorname{Slope}(\mathrm{VPD}) \\
(\mathrm{Tc}-\mathrm{Ta})_{u}=\operatorname{Intercept}+\operatorname{Slope}(\operatorname{VPsat}(\mathrm{Ta})-\operatorname{VPsat}(\mathrm{Ta}+\text { Intercept }))
\end{gathered}
$$

The conversion of the Apogee IR sensor WSN raw data into CWSI provides a

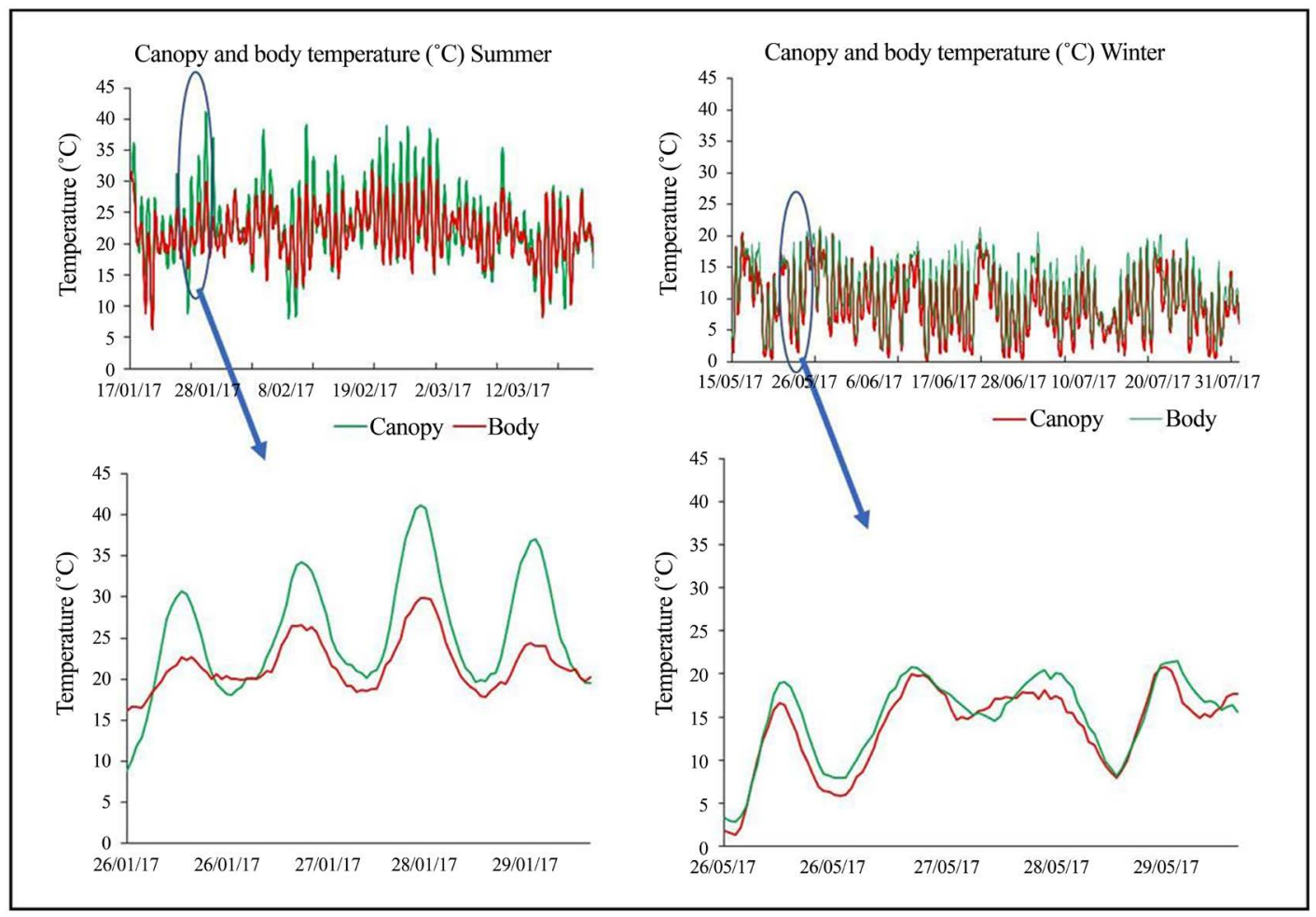

Figure 10. Canopy and body temperature measured for summer and winter. 
scheduling tool, and an alternative or complimentary sensor method to soil moisture monitoring.

\section{Conclusions}

We have developed customized wireless sensor networks and data transfer methods via cloud-based databases to smart phone apps and webpages. The advantages and disadvantages of different systems and their topologies have been reviewed, and the developed systems have been evaluated in field conditions for soil and crop monitoring. In addition, we provide examples of how continuous soil moisture data streams can be interpreted to track dynamic changes in soil hydraulic properties, for example temporal changes in field capacity over a series of wetting and drying cycles, and how radiometer sensors can be used to monitor crop water stress. These wireless sensor network technologies harness environmental data, converting them into timely information to support the decisions of land managers for tasks such as precision irrigation scheduling. There are opportunities to further develop these systems as new environmental sensors and communication methods become increasingly available.

To summarize, customized wireless sensor networks provide data at an unprecedented scale-both in space and time-and, through the harnessing of powerful data management systems (e.g. cloud-based databases) and smart algorithms, rapidly convert the data into critically valuable information for decision support systems needed to improve management of productive lands and reduce negative environmental impacts.

\section{Acknowledgements}

We thank Ben Jolly for helpful comments when reviewing this manuscript. We also acknowledge funding support from the New Zealand Ministry for Business, Innovation and Employment's "Maximising the Value of Irrigation" Program [contract number C09X1309].

\section{References}

[1] Tien, J.M. (2012) The Next Industrial Revolution: Integrated Services and Goods. Journal of Systems Science and Systems Engineering, 21, 257-296. https://doi.org/10.1007/s11518-012-5194-1

[2] Cukier, K. (2010) Data, Data Everywhere: A Special Report on Managing Information. The Economist, 394, 3-5.

[3] Rossiter, D.G. (2018) Past, Present and Future of Information Technology in Pedometrics. Geoderma, 324, 131-137. https://doi.org/10.1016/j.geoderma.2018.03.009

[4] Fischer, G., Tubiello, F.N., van Velthuizen, H. and Wiberg, D.A. (2007) Climate Change Impacts on Irrigation Water Requirements: Effects on Mitigation, 1990-2080. Technological Forecasting and Social Change, 74, 1083-1107. https://doi.org/10.1016/j.techfore.2006.05.021

[5] Knox, J.W., Kay, M.G. and Weatherhead, E.K. (2012) Water Regulation, Crop Production, and Agricultural Water Management-Understanding Farmer Perspec- 
tives on Irrigation Efficiency. Agricultural Water Management, 108, 3-8. https://doi.org/10.1016/j.agwat.2011.06.007

[6] Hedley, C.B., Knox, J.W., Raine, S.R. and Smith, R. (2014) Water: Advanced Irrigation Technologies. In: Alfen, N.K.V., Ed., Encyclopedia of Agriculture and Food Systems, Academic Press, Oxford, 378-406. https://doi.org/10.1016/B978-0-444-52512-3.00087-5

[7] Jury, W.A. and Vaux, H.J. (2007) The Emerging Global Water Crisis: Managing Scarcity and Conflict between Water Users. Advances in Agronomy, 95, 1-76. https://doi.org/10.1016/S0065-2113(07)95001-4

[8] Bogena, H.R., Herbst, M., Huisman, J.A., Rosenbaum, U., Weuthen, A. and Vereecken, H. (2010) Potential of Wireless Sensor Networks for Measuring Soil Water Content Variability. Vadose Zone Journal, 9, 1002-1013.

https://doi.org/10.2136/vzj2009.0173

[9] Vereecken, H., Kamai, T., Harter, T., Kasteel, R., Hopmans, J. and Vanderborght, J. (2007) Explaining Soil Moisture Variability as a Function of Mean Soil Moisture: A Stochastic Unsaturated Flow Perspective. Geophysical Research Letters, 34, L22402. https://doi.org/10.1029/2007GL031813

[10] Van Iersel, M.W., Dove, S. and Burnett, S.E. (2011) The Use of Soil Moisture Probes for Improved Uniformity and Irrigation Control in Greenhouses. Acta Horticulture, 893, 1049-1056. https://doi.org/10.17660/ActaHortic.2011.893.119

[11] Van Iersel, M.W., Chappell, M. and Lea-Cox, J.D. (2013) Sensors for Improved Efficiency of Irrigation and Nursery Production. HortTechnology, 23, 735-746.

[12] Coates, R.W., Delwiche, M. and Brown, P. (2005) Precision Irrigation in Orchards: Development of a Spatially Variable Microsprinkler System. Information and Technology for Sustainable Fruit and Vegetable Production, Montpellier, 12-16 September 2005, 611-624.

[13] Jones, H.G. (2007) Monitoring Plant and Soil Water Status: Established and Novel Methods Revisited and Their Relevance to Studies of Draught Tolerance. Journal of Experimental Botany, 58, 119-130. https://doi.org/10.1093/jxb/erl118

[14] Hedley, C.B. and Yule, I.J. (2009) Soil Water Status Mapping and Two Variable-Rate Irrigation Scenarios. Journal of Precision Agriculture, 10, 342-355. https://doi.org/10.1007/s11119-009-9119-Z

[15] Bakle, B.B. and Wagh, A.R. (2015) Smart Irrigation System Using Wireless Sensor Network and GPRS Module. International Journal of Modern Trends in Engineering and Research, 2, 1213-1218.

[16] Chappell, M., Dove, S.K., van Iersel, M.W., Thomas, P.A. and Ruter, J. (2013) Implementation of Wireless Sensor Networks for Irrigation Control in Three Container Nurseries. HortTechnology, 23, 747-753.

[17] Lea-Cox, Bauerle, J.D., van Iersel, W.L., Kantor, M.W., Bauerle, G.F., Lichtenberg, T.L., King, E. and Crawford, D.M. (2013) Advancing Wireless Sensor Networks for Irrigation Management of Ornamental Crops. An Overview. HortTechnology, 23, 717-724.

[18] Pan, L., Adamchuk, V.I., Martin, D.L., Schoeder, M.A. and Ferguson, R.B. (2013) Analysis of Soil Water Availability by Integrating Spatial and Temporal Sensor-Based Data. Precision Agriculture, 14, 414-433. https://doi.org/10.1007/s11119-013-9305-x

[19] Goumopoulos, C., O’Flynn, B. and Kameas, A. (2014) Automated Zone-Specific Irrigation with Wireless Sensor/Actuator Network and Adaptable Decision Support. Computers and Electronics in Agriculture, 105, 20-33. 
https://doi.org/10.1016/j.compag.2014.03.012

[20] ZigBee (2004) ZigBee Document 053474r06. Version 1.0, ZigBee Specification, ZigBee Alliance.

http://www.zigbee.org/wp-content/uploads/2014/11/docs-05-3474-20-0csg-zigbee-s pecification.pdf

[21] Perera, A. (2010) ZigBee Wireless Soil Moisture Sensor Design for Vineyard Management System. Masters Thesis, Auckland University of Technology, Auckland.

[22] Qandour, A. (2012) Application Framework for Wireless Sensor Networks. Doctorates and Masters Theses, Edith Cowan University, Joondalup.

[23] Sensors on Line (2008).

http://www.sensorsmag.com/components/what-a-mesh-part-2-networking-architec tures-and-protocols

[24] Hill, J.L. and Culler, D.E. (2002) Mica: A Wireless Platform for Deeply Embedded Networks. IEEE Micro, 22, 12-24. https://doi.org/10.1109/MM.2002.1134340

[25] Mapa, R.B., Green, R.E. and Santo, L. (1986) Temporal Variability of Soil Hydraulic Properties with Wetting and Drying Subsequent to Tillage. Soil Science Society of America Journal, 50, 1133-1138. https://doi.org/10.2136/sssaj1986.03615995005000050008x

[26] Logsdon, S.D. and Jaynes, D.B. (1993) Methodology for Determining Hydraulic Conductivity with Tension Infiltrometers. Soil Science Society of America Journal, 57, 1426-1431. https://doi.org/10.2136/sssaj1993.03615995005700060005x

[27] Logsdon, S.D. and Jaynes, D.B. (1996) Spatial Variability of Hydraulic Conductivity in a Cultivated Field at Different Times. Soil Science Society of America Journal, 60, 703-709. https://doi.org/10.2136/sssaj1996.03615995006000030003x

[28] Azevedo, A.S., Kanwar, R.S. and Horton, R. (1998) Effect of Cultivation on Hydraulic Properties of an Iowa Soil Using Infiltrometers. Soil Science, 163, 22-29. https://doi.org/10.1097/00010694-199801000-00004

[29] Moret, D. and Arrue, J.L. (2007) Dynamics of Soil Hydraulic Properties during Fallow as Affected by Tillage. Soil \& Tillage Research, 96, 103-113. https://doi.org/10.1016/j.still.2007.04.003

[30] Wei, H., Shao, M., Wang, Q., Fan, J. and Horton, R. (2009) Temporal Changes of Soil Hydraulic Properties under Different Land Uses. Geoderma, 149, 355-366. https://doi.org/10.1016/j.geoderma.2008.12.016

[31] Klute, A. (1982) Tillage Effects on the Hydraulic Properties of Soils: A Review. In: Kral, D.M. and Hawkins, S., Eds, Predicting Tillage Effects on Soil Physical Properties and Processes, American Society of Agronomy, Special Publication 44, Madison, 29-41.

[32] Onstad, C.A. and Voorhees, W.B. (1987) Hydrologic Soil Parameters Affected by Tillage. In: Logan, J.T., Davidson, J.M., Baker, J.L. and Overcash, M.R., Eds., Effects of Conservation Tillage on Groundwater Quality. Nitrates and Pesticides, Lewis, Chelsea, 95-112.

[33] Tempany, H.A. (1917) The Shrinkage of Soils. Journal of Agricultural Science, 8, 312-333. https://doi.org/10.1017/S0021859600002951

[34] Allmaras, R.R., Hallauer, E.A., Nelson, W.W. and Evans, S.E. (1977) Surface Energy Balance and Soil-Thermal Property Modifications by Tillage-Induced Soil Structure. Agricultural Experimental Station of the University of Minnesota, U.S.A Technical Bulletin 306, 44 p.

[35] Akram, M. and Kemper, W.D. (1979) Infiltration of Soils as Affected by the Pressure and Water Content at the Time of Compaction. Soil Science Society of Ameri- 
ca Journal, 3, 1080-1086. https://doi.org/10.2136/sssaj1979.03615995004300060004x

[36] Bauder, J.W., Randall, G.W. and Swan, J.B. (1981) Effect of Four Continuous Tillage Systems on Mechanical Impedance of a Clay Loam Soil. Soil Science Society of America Journal, 45, 802-806. https://doi.org/10.2136/sssaj1981.03615995004500040026x

[37] Hill, R.L. and Cruse, R.M. (1985) Tillage Effects on Bulk Density and Soil Strength of Two Mollisols. Soil Science. Society of. America Journal, 49, 1270-1273. https://doi.org/10.2136/sssaj1985.03615995004900050040x

[38] Voorhees, W.B., Evans, S.D. and Warnes, D.D. (1985) Effect of Preplant Wheel Traffic on Soil Compaction, Water Use, and Growth of Spring Wheat. Soil Science Society of America Journal, 49, 215-220. https://doi.org/10.2136/sssaj1985.03615995004900010043x

[39] Allmaras, R.R., Pikul, Jr., J.L., Kraft, J.M. and Wilkins, D.E. (1988) A Method for Measuring Incorporated Crop Residue and Associated Soil Properties. Soil Science Society of America Journal, 52, 1128-1133. https://doi.org/10.2136/sssaj1988.03615995005200040044x

[40] Hill, R.L., Horton, R. and Cruse, R.M. (1985) Tillage Effects on Soil Water Retention and Poresize Distribution of Two Mollisols. Soil Science Society of America Journal, 49, 1264-1270.

[41] McBride, J.F., Horton, R. and Thompson, M.L. (1987) Evaluation of Three Iowa Soil Materials as Liners for Hazardous-Waste Landfills. Iowa Academy of Science Journal, 94, 73-77.

[42] Kluitenberg, G.J., Horton, R., Thompson, M.L. and McBride, J.F. (1988) Recompact Iowa Soil Materials before Use as Liners for Waste Containment. Iowa Academy of Science Journal, 95, 114-116.

[43] Jackson, R.D. (1982) Canopy Temperature and Crop Water Stress. In: Hillel, D., Ed., Advances in Irrigation, Academic Press, New York, 43-85. https://doi.org/10.1016/B978-0-12-024301-3.50009-5

[44] Jackson, R.D. (1984) Remote Sensing of Vegetation Characteristics for Farm Management. SPIE, 475, 81-96.

[45] Jackson, R.D., Idso, S.B., Reginato, R.J. and Pinter Jr., P.J. (1981) Canopy Temperatures as a Crop Water Stress Indicator. Water Resources Research, 17, 1133-1138. https://doi.org/10.1029/WR017i004p01133

[46] Moran, M.S., Inoue, Y. and Barnes, E.M. (1997) Opportunities and Limitations for Image-Based Remote Sensing in Precision Crop Management. Remote Sensing of Environment, 61, 319-346. https://doi.org/10.1016/S0034-4257(97)00045-X

[47] Monteith, J.L. and Szeicz, G. (1962) Radiative Temperature in the Heat Balance of Natural Surfaces. Quarterly Journal of the Royal Meteorological Society, 88, 496-507. https://doi.org/10.1002/qj.49708837811

[48] Tanner, C.B. (1963) Plant Temperatures. Agronomy Journal, 55, 201-211. https://doi.org/10.2134/agronj1963.00021962005500020043x

[49] Bartholic, J.F., Namken, L.N. and Weigand, C.L. (1972) Arial Thermal Scanner to Determine Temperature of Soils and Crop Canopies Differing in Water Stress. Agronomy Journal, 64, 603-609. https://doi.org/10.2134/agronj1972.00021962006400050016x

[50] Hedley, C.B., Yule, I.J., Eastwood, Shepherd, T.G. and Arnold, G. (2004) Rapid Identification of Soil Textural and Management Zones Using Electromagnetic Induction Sensing of Soils. Australian Journal of Soil Research, 42, 389-400. https://doi.org/10.1071/SR03149 